Aneta Gołębiowska-Tobiasz, Michał Burzak

\title{
Remarks on the Status of Stelae in Countries of Eastern Europe. Research and Popularisation Postulates
}

Stone and wooden anthropomorphic stelae have been damaged since distant times, primarily due to adverse atmospheric conditions. However, the mass destruction of statues in Eastern Europe began in the $16^{\text {th }}$ century. A strip of steppe, until then controlled by the Crimean khans, started falling under the control of Polish political influences (Bessarabia, Wild Fields) and, in the following centuries, under Russian rule (areas of the Dnieper basin and then maritime areas to the mouth of Don, Volga Region and Ciscaucasia). With the weakening of the political role of Turkey and the elusion of the people subordinated to the Crimean khans, the steppe area was settled by people coming from Russia. This process started in the second half of the $17^{\text {th }}$ century and was most intense in the $18^{\text {th }}$ century. From that point, the fate of many stelae was determined. They have been destroyed during robbery excavations on kurgans conducted in the entire strip of steppe both by the peasantry and the gentry. Active actions of the Orthodox Church combating all preserved forms of older rituals over 300 years (from the $16^{\text {th }}$ century until the pre-revolutionary period) focused on anthropomorphic stelae, as they were considered a personification of evil spirits (Daszkiewicz, Tryjarski, 1982, 65). The Ukrainian peasantry instigated by monks contributed to the mass destruction of statues. In areas where stelae enjoyed the respect of local people, an order to destroy them was issued by tsarist administration authorities. They have been crushed and the stone has been re-used as a building material. Often entire sculptures were embedded into the foundations of churches or outhouses. The thoughtlessness of authorities can be demonstrated by an instance of using stone stelae for the construction of a basement on the premises of the head of district police in the 1870s (Novomoskovsk uyezd, Yekaterinoslav Governorate). The basement had walls made of stone babas set with their faces oriented to the centre of the room. At the entrance there were another two stelae (Daszkiewicz, Tryjarski, 1982, 68-69). From the second half of the $18^{\text {th }}$ century statues began to be used as mile stones (верстовые столбы) or road signs. In this way they got into regions where they had never been before, for example to the right bank of the Dnieper River, in the vicinity of Moscow, Ryazan, Stavropol. Throughout the entire next century statues from neighbouring worship places, still preserved, were brought

(cc) BY-NC-ND 
and embedded along post roads. In the Volga Region they were erected near to water sources or water holes. Stelae that were brought to mansions at the request of the gentry managed to survive these unfavourable conditions. Set in orchards, gardens or meeting places, they have been used as decorations. Frequently they became the founding artefacts in collections settled in the vicinity of museums.

Accounts of foreigners, tsarist officials, archaeologists, ethnographers, historians and lovers of antiquity travelling in the middle of the $19^{\text {th }}$ century inform us about the transport of stone stelae to mansions and the use of them as a building material in newly established villages. All these recollections have one thing in common - a fear of losing historical heritage. Authors, describing the thoughtlessness of the local people and acts of vandalism resulting from ignorance, deplored the appallingly low number of statues (widely quoted sources: Daszkiewicz, Tryjarski, 1982, 67-68, 71-72). From that period there are remarks about painting the stone stelae. It is extremely important information for archaeologists and conservators. During the contemporary conservation of relics, there is the chance to take samples of pigments preserved on the surface of sculptures. It is possible to date these samples after subjecting them to chemical analysis, because there are pigments with restricted chronological frameworks (e.g. Prussian blue, aniline pigments introduced in the $18^{\text {th }}$ and the $19^{\text {th }}$ centuries). Therefore, it is possible to accept or exclude the fact of polychroming statues by their creators. The information about painting babas in modern times helps to avoid mistakes with results obtained from tests carried on pigments.

In 1915 N. I. Veselovskyi lamented that immediately after including the steppe area into the Russian borders, the stone statues quickly began to be removed from kurgans. "Indulgence of local authorities in the work of destruction of stone babas caused a great and irreparable loss to Russian archaeology." These words by an archaeologist summarise the increasing rarity of stelae located in situ on kurgans. During the entire $20^{\text {th }}$ century, many mounds have been destroyed by deep ploughing. Sculptures found at such occasions have been broken to obtain building material, which was then traded. During the revolution, peasants frequently set stelae - as the former gentry - in their yards. Sometimes it happened that preserved fragments of statues were conveyed by a founder to museum institutions. During both World Wars, stelae located in gentry mansions were broken. Solders used statues as shooting targets, not even sparing collections deposited in museums. After the wars, this situation did not change. Stelae have still been treated as a building material. In villages they were used as benches, traditionally set in front of dwellings (Pletneva, 1974a, 8-9).

While the lack of education of the rural population could have been explained by harsh conditions during the wars and the post war period, its lack among people employed in museums can not be so excused. Low awareness of the 
archaeological, historical and ethnographic value of stelae among museum workers meant that the stelae were frequently abandoned within the museum premises or dug into adjacent greenery. Rarely stelae were placed indoors. They have never been subjected to conservation performed by professionals due to the assumption that the quantity of further exemplars discovered is greater than damages and losses. Conservation, in the opinion of museum workers from Eastern Europe, meant bonding broken or crumbling stelae with cement "pillars" that frequently caused further damage to soft kinds of rock. S. A. Pletneva deplored this practice $(1974 a, 10)$. The lack of interest in the fate of stelae, lack of legal regulations protecting these relics as the cultural heritage of the Ukraine, and their progressive degradation has been described by K. I. Krasilnikov in his monograph (1999, 60-62). Many exemplars of stelae documented by S. A. Pletneva in 1974 have since gone missing. Some have been destroyed thoughtlessly. In such way the collection in the Veliko-Anadol Forest Museum has become impoverished. Three well-preserved stelae documented in 1974 are now missing. They have probably been broken into small fragments. Only in was 2008 one of the exemplars located, however with the upper part of the body irreversibly destroyed. It is an open secret that stelae can be bought from private persons acquiring relics illegally - either from robbery of excavations, thefts or misappropriation. Due to the fact that many of the statues are not included in museum registers and still do not posses a record, the phenomena of disappearances remains difficult to detect (lack of records has been described, for example, by Pletneva, 1974a, in a descriptive part of the catalogue; Geraskova, 1991, 21-22).

Today, professional actions taken to protect anthropomorphic stelae should include the professional knowledge of complementary disciplines. In addition to archaeological excavations documenting new objects discovered in situ or secondarily acquired from illegal collections, petrography studies verifying the types of stone and helping locate the original deposits from which the material was obtained are also of great importance. Works of chemists, biologists and microbiologists provide scientific support to conservators. Chemical analysis allows, inter alia, for determining the degree of salinity of stone, types of layers, chemical composition of old mortars, adhesives and pigments. Thanks to microbiological studies, it is possible to establish the optimal method of biocide protection for each object. Analysis of the biological material, e.g. residual soil or macro-remains of the characteristic flora, deposited in cracks in the stone enables localisation or verification of the original positioning of objects. The monumental anthropomorphic sculpture is an excellent research material for historians (verification of information contained in written sources, localisation of winter quarters, places of worship, tracking the migration of population, etc.), ethnographers (reconstruction of the attire, burial rituals, continuation of traditions into the modern era, etc.), art historians (iconographic studies, stylistic 
and individual features of sculptures in relation to existing classifications or an area of occurrence, search for individual features of stonemasons) and niche specialties such as landscape archaeology or the history of worship.

Documentation of new findings should combine experiences of the abovementioned disciplines. In addition to archaeological documentation in the field, which should include photographic, illustrative, geodetic and descriptive documentation (context of findings, location, geographical relations, possibly aerial photographs of a site), and museum documentation (photographic, descriptive, drawing, entering a relic into a register, etc.), the objects should be provisionally prepared for conservation activities. In addition to documentation and description presenting exact technical conditions, it is recommended to make UV and IR photographs that allow the capture of possible paint layers. After taking conservation measures related to documentation, it is also necessary to perform a photographic session during works, prepare a descriptive register of all measures taken and show, in the form of descriptions and photographs, the condition of objects after completion of these works. Available modern methods often have the benefit of documenting and disclosing hard to capture details, such as the structure of a surface or plasticity of an object by using 3D scans or the development of a digital model of a statue. This facilitates comparative analyses, reconstructions, revisions of iconography or measures related to designing conservation and museum actions.

Rescuing stelae at the initial stage requires large amounts of money, taking into account their technical condition and methods of exhibition. Certainly, in the case of exemplars requiring professionally performed conservation, the person undertaking such measures must not only posses the appropriate educational background, but should also have extensive experience in working with monumental stone sculpture exhibited in natural conditions.

For some stelae that have been subjected to visual inspections by the authors, it would be sufficient only to sweep them from dust prophylactically and remove the more intensely bound dirt and overgrown plants with a soft brush and water (possibly with addition of surfactants). The release of the stone surface from secondary layers and microorganisms significantly slows the process of its degradation. In the case of exhibition inside buildings, a cleaned statue can wait for conservation measures for years. It is enough simply to sweep it regularly from dust and protect it from humidity and infestations of its surface by microorganisms. The process can be easily controlled by regular macroscopic observation. In the case of stelae presented in natural conditions, after cleaning the surface and in addition to preventive measures, it is necessary during autumn and winter to take measures protecting statues against rain, snow and wind. When the harmful activities of natural phenomena outlined above are detected, it is necessary to commence conservation measures as soon as possible. The full technical conservation including, inter alia, elimination of microorganisms with special chemical substances, strengthening weakened stone structures, vertical 
and horizontal insulation - separation of the lower parts of a statue from direct contact with the ground (soil, masonry, etc.) - and hydrofobisation allows a relic to be exhibited both inside and outside for many years.

When decisions are taken about full technical conservation, it is necessary to develop a programme of conservation measures for each object individually. Below, we present a general outline of the technical conservation which should be included:

1. removal of loose layers with soft brushes,

2. cleaning the surface from dirt with: water, water and detergent, steam, water under controlled and regulated pressure,

3. removal of sealing patina,

4. removal of secondary harmful layers,

5. desalination,

6. disinfection,

7. possible reinforcing impregnation,

8. injections of cracks,

9. filling cavities that threaten the sculpture's structure,

10. possible color unification of putties,

11. possible hydrofobing impregnation.

After completing the conservation, it is necessary to develop the optimal methodology for the exhibition plan, its design and implementation. Regardless of the selection of an exhibition location, objects need to be prepared to be displayed vertically. Therefore, the sculptures should be stabilised with frames, reconstructed "footrests" or "feet".

If conditions allow for the exhibition of a statue in situ, the first undertaking should be preparation of the preservation programme for the object enabling ongoing control of its condition. These objects should be obligatorily included in the catalogue of the nearest museum and their status should be inspected periodically. Specifications of the exhibition require cooperation between a competent museum and local institutions performing cultural and educational activities (schools, community centres, libraries). Where there are no such institutions, it is possible to engage people with developed historical awareness (teachers, education workers, enlightened representatives of religious organisations, etc.). After ensuring the safety of statues, it is possible to start preparing them for exhibition. In addition to stabilisation, it is necessary to provide vertical insulation for the statue, put in place water drainage, and protect it against the harmful activities of micro- and macro-organisms including controlling the growth of plants. The exhibition requires also constant conservatory care and the execution of periodical works involving gluing, disinfection and impregnation of stelae. Graphics and background information in a setting consistent with the exhibition values plays a crucial role. 
When a decision to exhibit a sculpture inside a museum building or exhibition pavilion is taken, it is recommended to develop a proper arrangement for illustration of a cult place, background information and graphics, light effects necessary to display the three-dimensional object, selection of artificial lightning and, depending on available financial resources, preparation of multimedia visualisation. Do not forget about providing favourable atmospheric conditions (air-conditioned exhibition halls). It is important to take steps for preventive conservatory measures involving cleaning a statue from dust, gluing weakened stone fragments, etc.

Outside exhibitions within museum premises requirethe seasonal protection of sculptures during autumn and winter by enclosing them within protective structures. It is also important to provide protection against thefts or vandalism, e.g. through monitoring.

Regardless of the exhibition place, the most important and most frequently overlooked measure is the lack of safety precautions during the transportation of stelae. Most modern mechanical damages are caused by incorrect estimations of the dimensions and weight of stelae and carelessness during loading and unloading the objects as well as due to inappropriate insulation and stabilisation during transportation.

The abovementioned activities are, more or less, subject to legal regulation, issued by state administrated authorities, developed research methods of scientific institutions, internal regulations of museums and educational units, etc. These norms are observed to varying degree, depending on many factors, such as the degree of knowledge, lack of tools to implement them, obsolescence of provisions, etc.

An important task is to establish an awareness of the cultural value of this category of relics among museum workers, archaeologists, ethnographers and other researchers having contacts with the art of stelae (not only the Polovtsians), as well as among the ordinary people living in European steppe countries. Monumental anthropomorphic statues that make a huge impression on researchers and tourists from Western Europe, are not seen by eastern European communities as a part of their cultural heritage. In the opinion of many people met by the authors, the anthropomorphic stelae were not worthy of interest or investment of efforts and resources for their rescue and display, because they did not arise such excitement as, for example, golden inventories from Scythian graves. Lack of awareness is certainly a consequence of specific situations in the post-Soviet countries and the tragic history of their citizens. The passage of time, however, as well as cultural approximation of newly constituted states to western European standards should target the activities of government and non-government organisations from the EU and Western Europe on filling these educational gaps, including improving awareness of the history and events of the past that took place in areas of this part of Europe long before 
episodes of modern history. This is linked to the protection of material heritage and its value for the national identity of both ethnic minorities of this region and larger nations. Numerous EU foundations as well as private funds are targeted to educational activities related to the development of national awareness in countries that have recently joined the EU. It would be appropriate that vanguards of these organisations become interested in the European heritage of Eastern Europe, which is rapidly and irreversibly vanishing from the territory of the same continent and, after all, constitutes part of a common cognitive value.

In addition to educational activities, targeted primarily at younger generations, it is also possible to take many measures that would essentially contribute to spreading knowledge about the monumental stone sculpture. Thanks to the development of modern communication systems it is possible to create Internet forums building awareness of the historical value of the art of stelae. Both interested people who are not professionals, and scientists working on issues related to stelae can develop mappings of objects, create a network of catalogues, where the location of objects can be registered, and publish their photographs or drawings. Then, it is possible to verify iconographic studies based on the available professional literature, press, Internet or any other available sources of information. These projects could be supervised by the archaeologists and conservatory authorities of a particular administrative unit.

In addition to publications concerning individual exemplars and collections issued by scientific publishers, addressed to a narrow group of professionals, there is scope to publish photo-catalogues or folders with descriptions of stelae, locally performed research, courses of conservations with maps of objects, edited in a form accessible for ordinary consumers of mass culture. Alongside tradition publications, e-books developed in several languages (including the local language and selected European languages) could also be a means of dissemination, particularly given their availability for the public.

Thank to such tools, it is possible to gather information about new findings, register their current location, inform about public or private bodies undertaking care for relics, and include them into stelae preservation projects. Virtual directories can and should be created in several different languages.

Local educational, cultural and museum centres should see the phenomena of monumental anthropomorphic sculpture as a chance for reviving tourism. Promoting stelae outside the Internet can be done through the press from local up to international levels. Objects can be promoted through the organisation of plein-airs, artistic contests and, at the museum level, through making them available for international exhibitions. An initiative to create a "Polovtsian temples trail", "Polovtsian stelae trail" (but also the "trail of Neolithic monuments of the pastoralism era", "Kimmerians sculpture trail", and "Scythian trail") would require cooperation between museum centres and authorities from the local and peripheral level. Each of the abovementioned exemplary 
tourist trails could connect the most distinctive and spectacular places related to particular archaeological cultures, historic objects or sites. In the case of the "Polovtsian trail", it could be archaeological reserves, where groups of kurgans, reconstructed and preserved Polovtsian temples, stelae in situ, stelae with historical locations, etc. are located, as well as field and museum collections of statues. Recently, reconstruction groups are becoming more and more popular. In addition to the dissemination of information about nomadic cultures at the local level, these groups could be involved by museum units in ongoing cultural cooperation including the monitoring of the condition of sites with stelae.

For local communities an important consequence of taking care of monuments is the inflow of funds. The already mentioned initiative to create tourist trails, highlighting sites and establishing archaeological reserves, is connected more broadly with the tourism industry. The development of tourist industries around local monuments in small villages works very well in states that recently joined the EU, such as: Poland, the Czech Republic, Slovakia, Hungary, Romania or Bulgaria. Over the past seven years, dynamics related to the tourism have grown significantly, especially in places attractive in terms of nature, history, ethnography or archaeology. The consequence is not only engagement of local people in the cultural development bringing significant profits (tourist guides, people working in the infrastructure, souvenir makers, reconstruction groups, etc.), but also a strong motivation for the care and protection of local monuments. Certainly, such activities should be controlled by a historian, archaeologist, ethnographer or an artist who is an expert in ancient times, to avoid the creation of a false image of historical phenomena. Countries of Eastern Europe have a great tourist potential, but unfortunately a lack of faith in the attractiveness of their own country, city, or local areas slows down the processes of economic and cultural development.

Thanks to modern means of global communication, it is possible to popularise issues related to monumental anthropomorphic sculptures as a unique phenomenon in both historical and global perspectives in broad social circles around Europe. Global communication is also related with the popularisation of nomadic cultures both early and late, whose impact on the progress of civilisation throughout Europe and changes to the material and spiritual culture of the entire continent is clear.

In the opinion of the authors, the monumental art of the nomads constitutes a corpus of relics that must be included in the UNESCO World Heritage List, before its last exemplars are irreversibly damaged. The art of stelae is a typical example of a "heritage without a successor". Preservation of relics belonging to that category in good condition should become an aim that will mobilise the scientific community and non-profit organisations throughout Europe to undertake actions rescuing them and stabilising their current situation. The exceptional testimony of the spiritual richness of Turkic nomads that evolved into the art of 
a great aesthetic value and high level of sculptural mastery must be preserved. For future generations of Europeans, this is a testimony of the rich history of the Black Sea Steppes and their impact on cultural changes in Central and Western European countries. For citizens of eastern European countries, it is a symbol of the identity and cultural heritage of their countries. For archaeologists, cultural anthropologists, ethnographers, historians with narrow specialties (history of cult, history of religion), art historians, geologists, and landscape archaeologists, this is a priceless source of knowledge. The presence of stelae on the prestigious UNESCO List would generate legal obligations primarily for the responsibilities of state administration structures in eastern European states, being owners of both large collections as well as individual exemplars (Russia, Ukraine, Lithuania, republics of the Northern Caucasus). Due to the political and economic situation in this region, these actions require the support of the whole of Europe. Inclusion on the List would be of immeasurable value, bringing with it the increased interest of researchers and the establishment of lasting contact and scientific cooperation between scientific institutions in Western and Eastern Europe. On a local scale it would give a chance for the development of the tourism industry, becoming a positive factor among societies in a part of Europe that requires various forms of support. The art of stelae, currently treated with indifference by the inhabitants of the steppe area, could become a chance for the economic and cultural revival of regions where, alongside their still pristine natural environments, it is the only historical source that could be compared with the grade A listed monuments from Central and Western Europe.

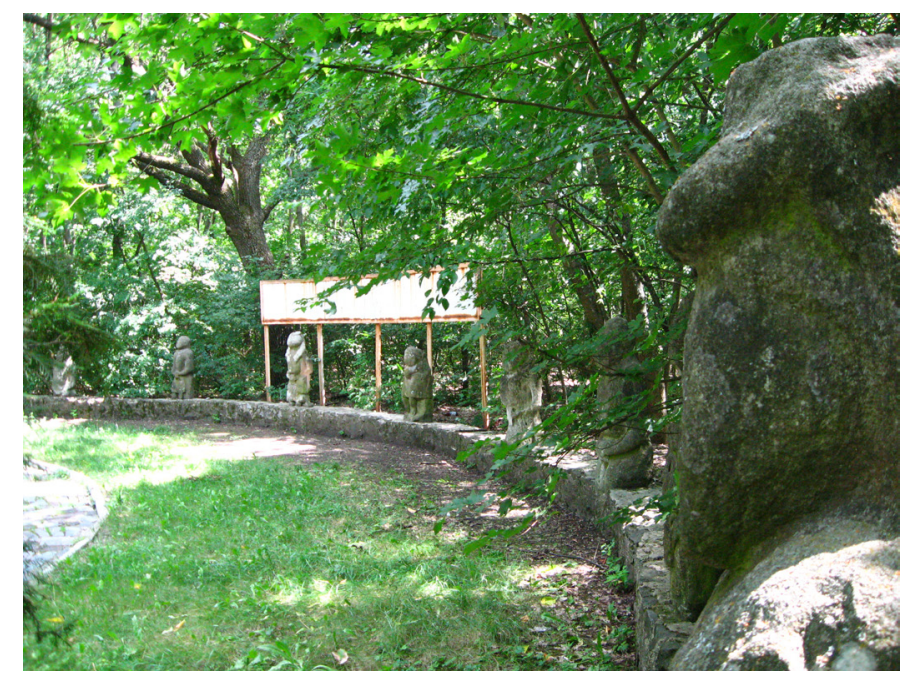

Fig. 7.1. The part of Polovtsians statues - waiting for the conservation in future. 
